PACS 31.15.-p; 33.20.-t

E. V. Pavlov, A. V. Ignatenko, S. V. Kirianov, A. A. Mashkantsev

Odessa State Environmental University, 15, L'vovskaya str., Odessa, 65016

E-mail: kirianovserg@gmail.com

\title{
DYNAMICAL AND TOPOLOGICAL INVARIANTS OF PbO DYNAMICS IN A RESONANT ELECTROMAGNETIC FIELD
}

\begin{abstract}
Nonlinear chaotic dynamics of the $\mathrm{PbO}$ molecule interacting with a resonant linearly polarized electromagnetic field is computed within the quantum model, based on the numerical solution of the Schrödinger equation and model potential method. To calculate the system dynamics in a chaotic regime the known chaos theory and non-linear analysis methods such as a correlation integral algorithm, the Lyapunov's exponents and Kolmogorov entropy analysis are used. There are listed the data of computing dynamical and topological invariants such as the correlation, embedding and Kaplan-Yorke dimensions, Lyapunov’s exponents, Kolmogorov entropy etc..
\end{abstract}

\section{Introduction}

At present time theoretical and experimental studying regular and chaotic dynamics of nonlinear processes in the different classes of quantum systems (in particular, atomic and molecular systems in an external electromagnetic field) attracts a great interest that is of a significant importance for multiple scientific and technical applications etc [1-9].

Some of the beauty of quantum chaos is that it has developed a set of tools which have found applications in a large variety of different physical contexts, ranging from atomic, molecular and nuclear physics optical) or resonators and mesoscopic physics and others (see [1-16]). According to Refs. [1-3], under the definite conditions, such systems are described by the corresponding model, when Hamiltonians are possessing only a few degrees of freedom. For the low-dimensional chaotic case the corresponding conditions of transition to deterministic chaos in the system dynamics are quite well understood at the classical level [1-4].

Under quantum treatment of the problem, the similar systems (in particular, the diatomic molecules in a resonant electromagnetic field) are studied with using the known quasiclassical approach [2]. At the theoretical level, the majority of studies, devoted to chaos phenomena in molecular dynamics, is carried out with the using simple tools of dynamical systems theory and qualitative theory of differential equations. New field of investigations of the quantum and other systems has been provided by the known progress in a development of a nonlinear analysis and chaos theory methods [1-12,17-30].

In Refs. [11,27-33] the authors applied different approaches to quantitative studying regular and chaotic dynamics of atomic and molecular systems interacting with a strong electromagnetic field and laser systems. The most popular approach includes the combined using the advanced non-linear analysis and a chaos theory methods such as the autocorrelation function method, multi-fractal formalism, mutual information approach, correlation integral analysis, false nearest neighbour algorithm, Lyapunov exponent's analysis, surrogate data method, stochastic propagators method, memory and Green's functions approaches etc (see details in Refs. [17-24]).

In Ref. [1-3,5-7] the authors performed a study of deterministic chaos in a number of diatomic molecules ( $\mathrm{GeO}, \mathrm{ZrO}$ etc) using as the quasiclassical method as quantum ones.

In this paper we present the corresponding results of computing the characteristic dynamical and topological invariants of the chaotic dynamics of the $\mathrm{PbO}$ molecule interacting with a linearly polarized resonant electromagnetic field. 


\section{Quantum-dynamical and chaos- geometric approach}

As the main ideas of the quantumdynamic approach to diatomic molecule in an electromagnetic field are in details presented in the Refs. [5-7], here we will restrict yourself only by some key elements. The quantumdynamic approach to a diatomic molecule in an electromagnetic field is based on the solution of the time-dependent Schrödinger equation, optimized operator perturbation theory and realistic model potential (density functional) method (see more details in Ref. [5]).

The problem of dynamics of diatomic molecules in an infrared field is reduced to solving the Schrödinger equation:

$$
i \partial \Psi / \partial t=\left[H_{0}+U(x)-d(x) E_{M} \varepsilon(t) \cos \left(\omega_{L} t\right] \Psi\right.
$$

where $E_{M}$ - the maximum field strength, $\varepsilon(t)=E_{0} \cos (\omega t)$ corresponds the pulse envelope (chosen equal to one at the maximum value of electric field).

A molecule in the field gets the induced polarization and its high-frequency component can be defined as $[3,5]$. It is important to remind that in the regular case of molecular dynamics, a spectrum will consist of a small number of the well resolved lines. In the case of chaotic dynamics of molecule in a field situation changes essentially. The corresponding energy of interaction with the field is much higher than anharmonicity constant $W>x h \Omega$. It is obvious that a spectrum in this case become more complicated $[5,6]$.

The main output data of the quantumdynamical approach application are the corresponding theoretical temporal dependence of polarization of a molecule in a resonant electromagnetic field the field in a chaotic regime.

In order to perform the detailed analysis of the chaotic regime polarization time series, further a total dynamics of the quantum system in an electromagnetic field and to calculate the fundamental topological and dynamical invariants of the system in a chaotic regime we used the universal chaos-geometric approach, presented earlier (see, c.g., [5-7,19-20]).

Generally speaking, the approach includes a set of such non-linear analysis and a chaos theory methods as the correlation integral approach, multi-fractal and wavelet analysis, average mutual information, surrogate data, Lyapunov's exponents and Kolmogorov entropy approach, spectral methods, nonlinear prediction (predicted trajectories, neural network etc) algorithms.

One of the important tasks here is to determine the corresponding embedding dimension and to reconstruct a Euclidean space $R^{d}$ large enough so that the set of points $d_{A}$ can be unfolded without ambiguity. In accordance with the embedding theorem, the embedding dimension, $d_{E}$, must be greater, or at least equal, than a dimension of attractor, $d_{A}$, i.e. $d_{E}>d_{A}$.

Usually one should use several standard approaches to reconstruction of the attractor dimension (see, e.g., [17-20]). The correlation integral analysis is one of the widely used techniques to investigate the signatures of chaos in a time series. The analysis uses the correlation integral, $C(r)$, to distinguish between chaotic and stochastic systems.

To compute the correlation integral, the algorithm of Grassberger and Procaccia is the most commonly used approach. According to this algorithm, the correlation integral is

$$
C(r)=\lim _{N \circledast 2} \frac{2}{N(n-1)} \sum_{\substack{i, j \\(1 \leq i<j \leq N)}} H\left(r-\left|\mathbf{y}_{i}-\mathbf{y}_{j}\right|\right)
$$

where $H$ is the Heaviside step function with $H(u)=1$ for $u>0$ and $H(u)=0$ for $u \leq 0, r$ is the radius of sphere centered on $\mathbf{y}_{i}$ or $\mathbf{y}_{j}$, and $N$ is the number of data measurements.

In order to perform the verification of the results obtained by means of the correlation integral analysis, one could use so called known surrogate data method. This approach makes use of the substitute data generated in accordance to the probabilistic structure underlying the original data.

The important dynamical invariants of a chaotic system are the Lyapunov's exponents 
(see, c.g., [17-20]). These characteristics can be defined as asymptotic average rates, they are independent of the initial conditions, and therefore they do comprise an invariant measure of attractor. Saying simply, the Lyapunov's exponents are the parameters to detect whether the system is chaotic or not.

Another important characteristics, namely, the Kolmogorov entropy $K_{\text {ent }}$ measures the average rate at which information about the state is lost with time. According to the definition, the Kolmogorov entropy can be determined as the sum of the positive Lyapunov's exponents.

The estimate of the dimension of the attractor is provided by the Kaplan and York conjecture:

$$
d_{L}=j+\frac{\sum_{\alpha=1}^{j} \lambda_{\alpha}}{\left|\lambda_{j+1}\right|}
$$

where $j$ is such that $\sum_{\alpha=1}^{j} \lambda_{\alpha}>0$ and $\sum_{\alpha=1}^{j+1} \lambda_{\alpha}<0$, and the Lyapunov's exponents $\lambda_{\alpha}$ are taken in descending order.

There are a few approaches to computing the Lyapunov's exponents. One of them computes the whole spectrum and is based on the Jacobi matrix of system. In this work we use an advanced algorithm with fitted map with higher order polynomials. To calculate the spectrum of the Lyapunov's exponents, one could determine the time delay $\tau$ and embed the data in the four-dimensional space. In this point it is very important to determine the Kaplan-York dimension and compare it with the correlation dimension, defined by the GrassbergerProcaccia algorithm].

As a rule, the calculational results of the state-space reconstruction are highly sensitive to the length of data set (i.e. it must be sufficiently large) as well as to the time lag and embedding dimension correctly determined.

Indeed, there are limitations on the applicability of chaos theory for observed (finite) dynamical variable series arising from the basic assumptions that these series must be infinite. A finite and small data set may probably result in an underestimation of the actual dimension of the process. The details of the procedures and algorithms used are presented in Refs. $[5,7,19-26]$.

\section{Some results and conclusions}

Here we present the results of numerical simulation of the time dynamics for diatomic molecule $\mathrm{PbO}$ in the electromagnetic field. The parameter $\mathrm{W}$ of interaction of an electromagnetic radiation with a molecule is as follows:

$$
W\left[\mathrm{~cm}^{-1}\right]=120.3\left(d_{0} / r_{0}\right)\left(S / M \omega_{e}\right)^{1 / 2}
$$

where, as usually, an electromagnetic field caan be characterized by the following parameter: $\mathrm{S}=c E / 8 \pi$ ( $c$ is the velocity of light and $E$ is a field strength), an interatomic distance $r_{0}$ in $\AA$, dipole moment $d_{o}$ in $\mathrm{D}, \omega_{e}$ in $\mathrm{cm}^{-1}, M$ in a.u.m., and the field parameter $S$ in GW/ $\mathrm{cm}^{2}$. The set of the $\mathrm{PbO}$ molecular constants and electromagnetic field parameters is listed in Table 1 [27]. The corresponding Chirikov parameter in this case is as:

$$
\delta n=2(E d / B)^{\frac{1}{2}} \gg 1 .
$$

The typical theoretical time dependence of polarization for $\mathrm{PbO}$ molecule in the field in a chaotic regime is presented in Ref. [5]. The concrete step is an analysis of the corresponding time series with the $n=7.6 \times 10^{3}$ and $\Delta t=5 \times 10^{-14} \mathrm{~s}$.

In Table 2 we present the calculational values of the correlation dimension $\mathrm{d}_{2}$, the KaplanYork attractor dimension $\left(d_{L}\right)$, the Lyapunov's exponents $\left(\lambda_{i}\right)$, Kolmogorov entropy $\left(\mathrm{K}_{\mathrm{entr}}\right)$,

Table 1.

Set of the PbO molecular constants and electromagnetic field parameters

\begin{tabular}{|c|c|}
\hline Parameters & PbO \\
\hline$\omega_{\mathrm{e}}=\hbar \Omega\left(\mathrm{cm}^{-1}\right)$ & 721.0 \\
\hline$\omega_{\mathrm{e}} \mathrm{x}_{\mathrm{e}}=x \hbar \Omega\left(\mathrm{cm}^{-1}\right)$ & 3.54 \\
\hline $\mathrm{B}_{\mathrm{e}}\left(\mathrm{cm}^{-1}\right)$ & 0.3073 \\
\hline $\mathrm{D}_{\mathrm{e}}\left(\mathrm{cm}^{-1}\right)$ & $2.23 \times 10^{-7}$ \\
\hline
\end{tabular}




\begin{tabular}{|c|c|}
\hline $\mathrm{d}_{0}(\mathrm{D})$ & 4.65 \\
\hline$r_{0}(\AA)$ & 1.92 \\
\hline $\mathrm{M}($ a.u.m $)$ & 14.86 \\
\hline $\mathrm{W}\left(\mathrm{cm}^{-1}\right)$ & $4.45-14.08$ \\
\hline
\end{tabular}

the Gottwald-Melbourne parameter. It is very important to declare that the dynamics of the $\mathrm{PbO}$ molecule in a resonant linearly polarized electromagnetic field has the elements of a deterministic chaos (the strange attractor).

Table 2.

Correlation dimension $d_{2}$, Lyapunov's exponents $(\lambda, i=1,2)$, Kaplan-York attractor dimension $\left(d_{L}\right)$, Kolmogorov entropy $\left(K_{\text {entr }}\right)$, Gottwald-Melbourne parameter $K_{\mathrm{GW}}$

\begin{tabular}{|c|c|c|}
\hline$d_{2}$ & $\lambda_{1}$ & $\lambda_{2}$ \\
\hline 2.87 & 0.151 & 0.0184 \\
\hline$d_{L}$ & $K_{\text {entr }}$ & $K_{\mathrm{GW}}$ \\
\hline 2.64 & 0.169 & 0.84 \\
\hline
\end{tabular}

From one side, this conclusion is entirely agreed with the results of modelling for other diatomic molecules [3,7-11]. From the other side, one should fix the increasing of the spectral chaos in the molecule studied in comparison with other diatomics such as $\mathrm{GeO}$ and similar ones. To conclude, the values of the dynamical and topological invariants (the correlation, KaplanYork dimensions, the Lyapunov's exponents etc) for the $\mathrm{PbO}$ molecule interacting with the resonant linearly polarized electromagnetic field are computed. In particular, the first two Lyapunov's exponents are positive. These data indicate on emerging dynamical chaos elements (indeed the low-dimensional attractor) in behaviour of diatomic molecule interacting with electromagnetic field.

\section{References}

1. Zhang C.; Katsouleas T.; Joshi C. Harmonic frequency generation \& chaos in laser driven molecular vibrations. In Proc. of Short- wavelength Physics with Intense Laser Pulses, San-Diego. 1993.

2. Berman, G.; Bulgakov, E.; Holm, D. Nonlinear resonance and dynamical chaos in diatomic molecule driven by a resonant IR field. Phys. Rev. A 1995, 52, 3074

3. López, G.; Mercado, A. classical chaos on double nonlinear resonances in diatomic molecules. J. Mod. Phys. 2015, 6, 496-509.

4. Glushkov, A.V. Spectroscopy of atom and nucleus in a strong laser field: Stark effect and multiphoton resonances. J. Phys.: Conf. Ser. 2014, 548, 012020.

5. Ignatenko A., Buyadzhi A., Buyadzhi V., Kuznetsova, A.A., Mashkantsev, A.A., Ternovsky E. Nonlinear chaotic dynamics of quantum systems: molecules in an electromagnetic field. Adv. Quant Chem. 2019, 78, 149-170.

6. Glushkov, A., Buyadzhi, V., Kvasikova, A., Ignatenko, A., Kuznetsova, A., Prepelitsa, G., Ternovsky, V. Non-Linear chaotic dynamics of quantum systems: Molecules in an electromagnetic field and laser systems. In: Quantum Systems in Physics, Chemistry, and Biology. Springer, Cham. 2017, 30, 169-180

7. Mashkantsev, A. A. ; Ignatenko, A.V. ; Kirianov, S.V. ; Pavlov, E.V. Chaotic dynamics of diatomic molecules in an electromagneic field. Photoelectronics. 2018, 27, 103-112.

8. Glushkov A., Ternovsky V., Buyadzhi V, Prepelitsa G. Geometry of a relativistic quantum chaos: New approach to dynamics of quantum systems in electromagnetic field and uniformity and charm of a chaos. Proc. Int. Geom. Center. 2014, 7(4), 60-71.

9. Glushkov A.V.; Ivanov, L.N. DC strongfield Stark effect: consistent quantum-mechanical approach. J. Phys. B: At. Mol. Opt. Phys. 1993, 26, L379-386.

10. Glushkov, A.; Lovett, L.; Khetselius, O.; Gurnitskaya E.; Dubrovskaya, Y.; Loboda A. Generalized multiconfiguration model of decay of multipole giant resonances applied to analysis of reaction $(\mu-\mathrm{n})$ on the nucleus ${ }^{40}$ Ca. Int. J. Mod. Phys. A. 2009, 24(2-3), 611-615. 
11. Serbov N., Svinarenko A. Wavelet and multifractal analysis of oscillations in system of couled autogenerators in chaotic regime. Photoelectr. 2006, 15, 27.

12. Serbov, N., Svinarenko, A. Wavelet and multifractal analysis of oscillations in a grid of couled autogenerators. Photoelectr. 2007, 16, 53-56.

13. Glushkov, A.V.; Khetselius, O.Yu.; Svinarenko, A.A.; Serbov, N.G. The sea and ocean 3D acoustic waveguide: rays dynamics and chaos phenomena, J. Acoust. Soc. Amer. 2008, 123(5), 3625.

14. Glushkov A.V., Serbov N.G., Bunyakova Yu.Ya., Prepelitsa G.P., Svinarenko A.A. Sensing the kinetical features of energy exchange in mixture CO2-N2-H20 of atmospheric gases under interacting with laser radiation. Sensor Electr. and Microsyst. Techn. 2006. N4. P.20-22.

15. Danilov, V., Kruglyak, Y., Pechenaya, V. Electron density-bond order matrix and the spin density in the restricted CI method. Theor. Chim Acta. 1969, 13(4), 288-296.

16. Danilov, V., Kruglyak, Y., Kuprievich, V., Ogloblin, V. Electronic aspects of photodimerization of the pyrimidine bases and of their derivatives. Theor. Chim.Acta. 1969, 14(3), 242-249.

17. Abarbanel, H.; Brown, R.; Sidorowich, J; Tsimring, L. The analysis of observed chaotic data in physical systems. Rev. Mod. Phys. 1993, 65, 1331- 1392.

18. Kennel, M.; Brown, R.; Abarbanel, H. Determining embedding dimension for phasespace reconstruction using geometrical construction. Phys. Rev. A. 1992, 45, 34033412 .

19. Glushkov, A.V. Methods of a Chaos Theory. Astroprint: Odessa, 2012.

20. Khetselius, O. Forecasting evolutionary dynamics of chaotic systems using advanced non-linear prediction method In Dynamical Systems Applications; Łódz, 2013; Vol T2, pp 145-152.

21. Glushkov A., Khetselius O., Bunyakova Yu., Prepelitsa G., Solyanikova E., Serga E. Non-linear prediction method in short-range forecast of atmospheric pollutants: low-dimensional chaos. In: Dynamical Systems Theory and Applications. Lodz Univ. 2011, LIF111

22. Glushkov A., Khetselius O., Kuzakon V., Prepelitsa G., Solyanikova E., Svinarenko A. Modeling of interaction of the non-linear vibrational systems on the basis of temporal series analyses (application to semiconductor quantum generators). Dynamical Systems - Theory and Applications. Lodz. 2011, BIF110.

23. Glushkov, A.., Safranov, T., Khetselius, O., Ignatenko, A., Buyadzhi, V., Svinarenko, A. Analysis and forecast of the environmental radioactivity dynamics based on methods of chaos theory: General conceptions. Environm. Probl.. 2016, 1(2), 115-120.

24. Glushkov, A., Khetselius, O., Serbov, N., Svinarenko, A., Buyadzhi, V. Dynamics of multi-layers neural networks on bais of photon echo: Effects of chaos and stochastic resonance. Proc. of Int.. Conf. on Statistical Phys. Crete. 2008, 26

25. Bunyakova Yu.; Glushkov, A.; Fedchuk A; Serbov N.; Svinarenko A.; Tsenenko, I. Sensing non-linear chaotic features in dynamics of system of coupled auto generators: multifractal analysis, Sensor Electr.\& Microsyst. Techn. 2007, 1,14-17

26. Glushkov, A.V.; Buyadzhi, V.V.; Ponomarenko, E.L. Geometry of Chaos: Advanced approach to treating chaotic dynamics in some nature systems. Proc. Int. Geom. Center. 2014 7(1),24-30.

27. Oolg, M.; Nicklass, A.; Stoll, H. On the dipole moment of PbO. J. Chem. Phys. 1993, $99(5), 3614$. 
PACS 31.15.-p; 33.20.-t

E. V. Pavlov, A. V. Ignatenko, S. V. Kirianov, A. A. Mashkantsev

\title{
DYNAMICAL AND TOPOLOGICAL INVARIANTS OF PbO DYNAMICS IN A RESONANT ELECTROMAGNETIC FIELD
}

\begin{abstract}
Summary. Nonlinear chaotic dynamics of the $\mathrm{PbO}$ molecule interacting with a resonant linearly polarized electromagnetic field is computed within the quantum model, based on the numerical solution of the Schrödinger equation and model potential method. To calculate the system dynamics in a chaotic regime the known chaos theory and non-linear analysis methods such as a correlation integral algorithm, the Lyapunov's exponents and Kolmogorov entropy analysis are used. There are listed the data of computing dynamical and topological invariants such as correlation, embedding, Kaplan-Yorke dimensions, Lyapunov's exponents etc.
\end{abstract}

Key words: Chaotic dynamics, diatomic molecule, electromagnetic field

PACS 31.15.-p; 33.20.-t

\author{
Е. В. Павлов, А. В. Игнатенко, С. В. Кирьянов, А. А. Машканцев
}

\section{ДИНАМИЧЕСКИЕ И ТОПОЛОГИЧЕСКИЕ ИНВАРИАНТЫ ДИНАМИКИ МОЛЕКУЛЫ РЬО В РЕЗОНАНСНОМ ЭЛЕКТРОМАГНИТНОМ ПОЛЕ}

Резюме. Нелинейная хаотическая динамика молекулы $\mathrm{PbO}$ в резонансном линейно поляризованным электромагнитным поле рассчитывается в рамках квантовой модели, базирующейся на численном решении уравнения Шредингера и методе модельного потенциала. Для моделирования динамики в хаотическом режиме используются известные методы нелинейного анализа и теории хаоса, в т.ч., метод корреляционного интеграла, анализ на основе показателей Ляпунова, энтропии Колмогорова и др. Представлены данные вычисления динамических и топологических инвариантов, в т.ч., размерностей вложения, корреляционной, Каплана-Йорка, показателей Ляпунова, др.

Ключевые слова: хаотическая динамика, 2-атомная молекула, электрическое поле

PACS 31.15.-p; 33.20.-t

С. В. Павлов, Г. В. Ігнатенко, С. В. Кір'янов, О. А. Машканцев,

\section{ДИНАМІЧНІ І ТОПОЛОГІЧНІ ІНВАРІАНТИ ДИНАМИКИ МОЛЕКУЛИ РЬО У РЕЗОНАНСНОМУ ЕЛЕКТРОМАГНІТНОМУ ПОЛІ}

Резюме. Нелінійна хаотична динаміка молекули $\mathrm{PbO}$, взаємодіючей 3 резонансним лінійно-поляризованим електромагнітним полем, розраховується в рамках квантової моделі на основі рішення рівняння Шредінгера і методу модельного потенціалу. Для аналізу динаміки системи в хаотичному режимі використані методи нелінійного аналізу та теорії хаосу, у т.ч., метод кореляційного інтеграла, аналіз на основі показників Ляпунова, ентропії Колмогорова т.і. Надані дані обчислення динамічних і топологічних інваріантів: розмірностей кореляційної, вкладення, Каплана-Йорка, показників Ляпунова, та інших.

Ключові слова: хаотична динаміка, 2-атомна молекула, електромагнітне поле 